\title{
Microstructure and mechanical performance of dissimilar metal joints of aluminium alloy and stainless steel by cutting-assisted welding-brazing
}

Huibin Xu ( $\sim$ hbxu@cqut.edu.cn )

Chongqing University of Technology

\section{Wei Cong}

Chongqing University of Technology

Donghua Yang

Chongqing University of Technology

Yanlong Ma

Chongqing University of Technology

Wanliang Zhong

Chongqing University of Technology

Pan Tan

Chongqing University of Technology

Jiuchun Yan

Harbin Institute of Technology

\section{Research Article}

Keywords: Dissimilar metal joining, Welding-brazing, Cutting tool, Microstructure, Intermetallic compound, Tensile strength

Posted Date: August 30th, 2021

DOI: https://doi.org/10.21203/rs.3.rs-844889/v1

License: (c) (1) This work is licensed under a Creative Commons Attribution 4.0 International License. Read Full License

Version of Record: A version of this preprint was published at The International Journal of Advanced Manufacturing Technology on January 11th, 2022. See the published version at https://doi.org/10.1007/s00170-021-08452-x. 
Microstructure and mechanical performance of dissimilar metal joints of aluminium alloy and stainless steel by cutting-assisted weldingbrazing

Huibin $\mathrm{Xu}^{1, *}$, Wei Cong ${ }^{1}$, Donghua Yang ${ }^{1}$, Yanlong $\mathrm{Ma}^{1}$, Wanliang Zhong ${ }^{1}$, Pan Tan ${ }^{1}$, Jiuchun Yan,

${ }^{1}$ College of Material Science and Engineering, Chongqing University of Technology, Chongqing 400054, China

${ }^{2}$ State Key Laboratory of Advanced Welding and Joining, Harbin Institute of Technology, Harbin 150001, China

*Corresponding author: E-mail: hbxu@cqut.edu.cn (Huibin Xu); jcyan@hit.edu.cn (Jiuchun Yan) 


\section{Microstructure and mechanical performance of dissimilar metal joints of aluminium alloy and stainless steel by cutting-assisted welding- brazing}

Abstract: The 5052 aluminium alloy and 304 stainless steel were successfully joined by cutting-assisted welding-brazing (CAWB) method without using flux. Dual-scale interfacial structures were achieved by manipulating the cutting tool profile. Results indicated that the macro-scale interfacial structure was produced at the joint interface when the taper step-shape cutting tool was adopted. As the cutting tool step was increased to 6-step, the micro-scale interface took on serrated morphology and a layer of continuous and wavy intermetallic compound (IMC) with an average thickness of $3.3 \mu \mathrm{m}$ was formed at the interface. The $\tau_{4}$ IMC particles and the $\mathrm{FeAl}_{6}$ phases on a small scale were dispersed homogeneously in the welded seam. The maximum tensile strength of the joints reached 152.3 MPa upon tensile loading, $75 \%$ that of the 5052 aluminium base metal. The strong and reliable Al/steel dissimilar joints were attributed to the particle reinforced weld metal and the macro- and micro-scale dual self-locking structure at the interface.

Keywords: Dissimilar metal joining; Welding-brazing; Cutting tool; Microstructure; Intermetallic compound; Tensile strength

\section{Introductions}

The light-weight alloy of $\mathrm{Al} /$ steel is increasingly attracting attention in the shipbuilding, aerospace and automotive industries [1]. However, the low weldability of aluminum and steel has severely restricted their use. Usually, brittle and hard Fe-Al intermetallic compound (IMC), such as $\mathrm{FeAl}_{3}$ and $\mathrm{Fe}_{2} \mathrm{Al}_{5}$ phases, form easily at the joint interface during welding process, which can be an important internal cause for formation of crack in joint [2].

In recent years, there has been an increasing interest on the part of academics in the integration of technologies with a lower thermal cycle [3]. Among these joining 
methods, the technology of welding-brazing aluminium alloy to steel with good flexibility has been increasingly considered [4]. Furuya et al. [5] reported that the thickness of the IMC layer has been reduced by adding appropriate quantities of Si and Ti elements, and that the joint strength has been improved. He et al. [6] successfully joined aluminium and steel by pulsed TIG welding-brazing with high-frequency induction twin hot wire technology. They found that the reduction of IMC layer was achieved by controlling the heat input. Wu et al. [7] achieved the joining of aluminium and steel with ultrasonic-assisted TIG welding-brazing. It proved that the weldingbrazing process by introducing external energy could obtain the high joint properties, and the maximum joint strengthen was owed to fine-grained strengthening and dispersing strengthening of precipitated phases in the welded seam. In our previous study [8], attempts have already been made to join $\mathrm{Al} /$ steel by arc brazing technology. The maximum shear strength of the joints interface reached $182 \mathrm{MPa}$, and the IMC thickness can be effectively obtained as thin as $1.2 \mu \mathrm{m}$. However, the obtained interfacial microstructure was still relatively straight, which was difficult to hinder crack propagation. Based on it, one may expect that further improvement in bonding strength of $\mathrm{Al} /$ steel joint can be obtained if manipulating the cutting tool profile to achieve a unique combination of interfacial structure and strength. Moreover, the problem of the large difference in coefficients of thermal expansion (CTE) of Al/steel dissimilar metals was still existed [9]. Therefore, a cutting-assisted welding-brazing (CAWB) method without using of flux was proposed and applied in joining of aluminium alloy to stainless steel.

The aim of this study is to investigate the effect of two cutting tool types (tapershape and taper-step shape) on the welding-brazing features of the joints. First, the macrostructure of the joints under two cutting tool types were observed and compared. 
Then interfacial microstructure evolution was evaluated, and the distribution of precipitated phases in welded seam was preliminary discussed. Finally, the formation mechanisms of the joints were analysed to reveal the influence of cutting tool profiles and the joint microstructure on the tensile properties.

\section{Experimental procedures}

$5052 \mathrm{Al}$ and 304 stainless steel strips of $100 \mathrm{~mm} \times 50 \mathrm{~mm} \times 3 \mathrm{~mm}$ were adopted as the base metal. ER4043 weld wire (Al-5Si wt.\%) with a diameter of $1.6 \mathrm{~mm}$ was used as a filler metal. Their corresponding chemical compositions of base materials and filler metal as shown in Table 1 and Table 2, respectively.

Before welding-brazing, the surface of the base metal was cleaned with abrasive paper and acetone to remove the oil contamination and oxide film. As seen in Fig. 1, in order to achieve the action effect of the molten pool stirring in the CAWB welding process, the distance of tungsten electrode and milling cutter was set to $8.3 \mathrm{~mm}$, and the inclination angle of the cutting tool was $68.5^{\circ}$, the angle between the tungsten electrode and the horizontal plane was $75^{\circ}$. The welding-brazing process was carried out on a WX-300 welding source with a welding current of $102 \mathrm{~A}$, an arc length of $3 \mathrm{~mm}$, an offset value for cutting was $0.2 \mathrm{~mm}$, a $0.25 \mathrm{~mm}$ butt gap was pre-set in the assembly process, a filler metal feed speed of $760 \mathrm{~mm} / \mathrm{min}$, a welding speed of $44 \mathrm{~mm} / \mathrm{min}$, and an argon flow rate of $15 \mathrm{~L} / \mathrm{min}$. Subsequently, a cutter inserted in a pool at a rotation speed of $3500 \mathrm{rpm}$ starts to cut stainless steel and stir pool.

In this study, YG-6x steel (WC-Co cemented carbide) was used as CAWB cutting tool material. The welding process was investigated by changing the profile of cutting tool (taper-shape cutting tool and taper step-shape cutting tool). As shown in Fig. 2(a), the taper-shape cutting tool was a simple truncated cone. The second type was taper step-shape cutting tool, which was machined with a $6.5 \mathrm{~mm}$-diameter shoulder, a $2 \mathrm{~mm}$ - 
diameter small end and a $4 \mathrm{~mm}$-diameter large end. The cutting tool pin was $4 \mathrm{~mm}$ long with different steps ( $\mathrm{N}$ was 2, 4, 6, 7), as shown in Fig. 2(b).

After welding-brazing, the microstructure of the joints was measured by scanning electron microscopy (SEM). The composition of the joints was analyzed with an energy dispersive spectrometer (EDS) and X-ray diffraction (XRD). The IMC layer thickness and the ratio of precipitated phase were calculated using the image pro plus software. Fig. 3 shows the geometry and dimensions of tensile specimens. The tensile strength of the joints without reinforcement was tested on a WDW-E200 universal testing machine with a loading rate of $1 \mathrm{~mm} / \mathrm{min}$ at room temperature. At least three samples were tested under the same condition to maintain the accuracy of the tensile tests.

\section{Results and discussion}

\subsection{Joint formation without cutting tool}

Fig. 4 presents the cross-section of the joint without using cutting tool. A typical fusion-welded joint with the aluminum alloy base material was obtained. However, there was no effective connection at the joint interface without the aid of a cutting tool. Since the oxide film still existed on the surface of steel substrate, which hinders the wetting and spreading of the liquid filler metal on the steel surface, thereby forming the unbounded interface.

\subsection{Macro and microstructure evolution of CAWB joints interface}

Fig. 5 shows the CAWB joint morphologies with different cutting tool profiles. As shown in Fig. 5(a), the interface morphology of the joint was relatively straight, and voids and un-stripping steel chips gathered near the steel substrate. This is due to the limited cutting and stirring capabilities of the taper cutting tool, resulting in the formation of defects. As the cutting tool steps increased from 4 to 7, the macroscopic 
wave of the joints changed significantly, but the amplitude has not changed remarkably was observed in Fig. 5(b-d). Fig. 5(e) presents the schematic diagram of wavelength and amplitude while Fig. 5(f) calculates the corresponding wavelength and amplitude values. As the steps number increased from 2 to 7, the values of average wavelength were about $1999.4 \mu \mathrm{m}, 1052.5 \mu \mathrm{m}, 628.8 \mu \mathrm{m}$ and $534.7 \mu \mathrm{m}$, respectively, as shown in Fig. 5(f). Nevertheless, the values of the wave's amplitude have only slightly changed. The values of average amplitude were about $518.4 \mu \mathrm{m}, 119.5 \mu \mathrm{m}, 158.6 \mu \mathrm{m}$ and 133.9 $\mu \mathrm{m}$ when the step number was 2, 4, 6, and 7, respectively. Finally, the typical symmetrical waves and macro self-locking structures were obtained at the joint interface, which would be achieved the strong mechanical meshing effect [10].

It was a crucial issue to control the formation and growth of the IMC layer at the joint interface in order to achieve welding-brazing $\mathrm{Al} /$ steel joints with high mechanical strength. To clarify the effect of cutting tool profiles on the joint IMC, interfacial microstructure and chemical components of four joints was characterized and the corresponding EDS results as shown in Table 3. Fig. 6 presents the microstructure of CAWB joint with different cutting tool profiles while Fig. 7 shows the corresponding thickness of interfacial IMC layers and EDS line scanning result.

As shown in Fig. 6(a and b), the lager-scale steel chips were distributed inside the IMC layer, which provided a large amount of Fe atoms for the formation of a thick IMC layer. Finally, crack and laminated-like reaction layer with a maximum thickness of 53 $\mu \mathrm{m}$ was obtained, and this would be easy to induce the crack propagation and deteriorate the joint mechanical properties. According to the Fe-Al-Si ternary phase diagram [11] and EDS analysis given in Table 3, the phases (marked by point A) was $\eta$ $(\mathrm{Fe}, \mathrm{Cr})_{2}(\mathrm{Al}, \mathrm{Si})_{5}$. As the number of cutting tool steps increased to 4 , the steel substrate has an undergone obvious plastic deformation, given in Fig. 6(c and d). No steel chips 
aggregation was found at the interface while swirl-like morphology appeared, indicated that an insufficient action of cutting occurred under this condition. Consequently, IMC layer with an average thickness of $12.9 \mu \mathrm{m}$ formed at the joint interface as shown in Fig. 6(d). According to the EDS results shown in Table 3, it can be determined that the point B (Fig. 6(d)) was $\tau_{5}-\mathrm{Al}_{8}(\mathrm{Fe}, \mathrm{Cr})_{2} \mathrm{Si}$ phase [12].

Fig. 6(e-f) presents the joint interface (cutting tool step number was 6). The joint interface appeared periodically serrated with a continuous and wavy distribution IMC layer. And some block-like IMC particles migrated towards the interface as seen in Fig. 6(e). The EDS analysis at point $\mathrm{C}$ and D shown that the block-like IMC particles were $\tau_{4}-(\mathrm{Fe}, \mathrm{Cr})(\mathrm{Al}, \mathrm{Si})_{5}$ phase, and the IMC layer with thickness of $3.3 \mu \mathrm{m}$ was identified to be $\tau_{5}-\mathrm{Al}_{8}(\mathrm{Fe}, \mathrm{Cr})_{2} \mathrm{Si}$ phase, respectively. As shown in EDS linear scanning result (Fig. 7a), the $\mathrm{Si}$ and $\mathrm{Cr}$ elements were detected in $\tau_{5}-\mathrm{Al}_{8}(\mathrm{Fe}, \mathrm{Cr})_{2} \mathrm{Si}$ layer. Furthermore, the $\mathrm{Si}$ element content was significantly increased at the interface between the IMC layer and welded seam. Many previous studies reported that the addition of Si element to Al alloys was able to suppressing the formation of Fe-Al reaction layer [17]. It was indicated that the cutting tool could be force these alloy elements to participate in the reaction of Fe-Al IMC layer, resulting in reducing the thickness of IMC layer and caused grain refinement of the $\tau_{5}-\mathrm{Al}_{8}(\mathrm{Fe}, \mathrm{Cr})_{2} \mathrm{Si}$ phase. Therefore, when the cutting tool step was 6 , the average IMC layer thickness reached the minimum value and the tensile strength of the joints was $152.3 \mathrm{MPa}$. It indicated that the 6-step cutting tool could realize the reduction of IMC thickness and formation of macro and micro-scale dual self-locking interface, which was beneficial to enhance the tensile properties of the joints.

With the cutting tool steps increasing to 7 , manifested in a relatively straight joint interface with micro-crack defects in the joint, as shown in Fig. 6(g-h). Composition 
analysis at points $\mathrm{E}$ and $\mathrm{F}$, shown that the two phases were $\eta-(\mathrm{Fe}, \mathrm{Cr})_{2}(\mathrm{Al}, \mathrm{Si})_{5}$ and $\tau_{5^{-}}$ $\mathrm{Al}_{8}(\mathrm{Fe}, \mathrm{Cr})_{2} \mathrm{Si}$, respectively. The micro-cracks propagated between the two layers of IMC and its average thickness was $3.9 \mu \mathrm{m}$. It should be noted that the cutting effort and IMC layer reduction was not always improved by increasing the number of cutting tool step. It indicated that the action of seven steps cutting tool was insufficient and unsuitable. Finally, it would weaken the tensile properties of the joints.

\subsection{Microstructure evolution of the welded seam}

Fig. 8 presents the microstructure of the welded seam using different cutting tool profiles and the corresponding EDS results as shown in Table 4. Fig. 9 shows the relationship of the precipitated $\mathrm{Fe}-\mathrm{Al}$ phase ratio to the profile of the cutting tool.

In the process of welding-brazing $\mathrm{Al} /$ steel without using of cutting tool, the obtained joint has obvious unbound characteristics (seen in Fig. 4), which greatly hinders the diffusion process of iron atoms to the welded seam. And the welded seam was only made up of gray matrix and white rod-like phases given in Fig. 8(a, b). According to the EDS analysis showed that the gray matrix was the $\alpha$-Al phase and the white rod-shaped structure (marked as point A in Fig. 8b) was identified as the Al-Si eutectic phase.

During the CAWB process using taper cutting tool, the oxide film on the steel surface was removed, which greatly accelerated the dissolution of $\mathrm{Fe}$ atoms into the molten pool. However, a large number of net-like precipitates were produced in the welded seam (Fig. 8(c, b)), and the EDS analysis showed that this structure (marked as B) was determined in the $\mathrm{FeAl}_{6}$ phase $[13,14]$. As seen in Fig. 9, the area ratio of $\mathrm{FeAl}_{6}$ phase was $11.1 \%$. These large-scale and net-like $\mathrm{FeAl}_{6}$ phases could increase the brittle nature of the joint.

When the cutting tool step number increased to six, the obtained welded seam was 
mainly made up of block-like phases and small-scale $\mathrm{FeAl}_{6}$ phase, which was a uniform distribution in the welded seam (Fig. 8(e, f)). At the magnified SEM images of point $\mathrm{C}$ in Fig. 8(f), and the block-like phases were identified as $\tau_{4}$ phase with $\mathrm{Cr}$ solid solution. In addition, the block-like IMC particles were predominant in the welded seam, and the area ratio of IMC particles and $\mathrm{FeAl}_{6}$ phase was $4.2 \%$ and $2.3 \%$, respectively. It should be noted that IMC particles can be generated from the transformation of steel chips or cut from the IMC layer. The stirring capacity of the cutter tool has been strengthened, which would help break the $\mathrm{FeAl}_{6}$ phase on a large scale under the 6-step cutter tool. In addition, these uniformly dispersed IMC particles and small-scale $\mathrm{FeAl}_{6}$ phases could be considered as strengthening phases, which had the potential to improve the joints tensile properties [15]. Finally, the large difference in coefficient of thermal expansion (CTE) of Al/ steel joints could be effectively alleviated.

\subsection{Tensile properties and fracture analysis}

Fig. 10(a) presents the effect of cutting tool profiles on the tensile strength of joints. It can be seen that the joints tensile strength first increased and then decreased. Particularly, the maximum tensile strength of the joints was $152.3 \mathrm{MPa}, 75 \%$ that of the 5052 aluminum base metal under the 6-step cutting tool. According to XRD analysis seen in Fig. 10(b), this proved that the Fe, $\alpha-\mathrm{Al}$ and $\tau_{5}-\mathrm{Al}_{8} \mathrm{Fe}_{2} \mathrm{Si}$ phases were existed on the steel fractured surface. In addition, the energy spectrum results show that the phase (marked as I) in Fig. 10(c) was identified as $\tau_{5}-\mathrm{Al}_{8} \mathrm{Fe}_{2} \mathrm{Si}$ phase (71.33 at.\% $\mathrm{Al}, 11.25$ at.\% Si, 3.71 at.\% $\mathrm{Cr}, 13.70$ at.\% Fe). The EDS identified results of the fracture surface agree with quantitative one confirmed by XRD pattern. Moreover, the fracture surface of the joint was analysis as shown in Fig. 10(c and d), the fracture mode was quasicleavage fracture with tearing ridges. Therefore, it suggested that the fracture path appeared not only in the welded seam, but also at the interface between the $\tau_{5}-\mathrm{Al}_{8} \mathrm{Fe}_{2} \mathrm{Si}$ 
layer and the steel base metal. Adopting the 6-step cutting tool, the Al/steel joint had the highest tensile strength among these five joints. Therefore, a medium cutting tool profile was important for a sounder joint.

\subsection{Joint formation mechanism}

Based on the above findings, the new CAWB process for $\mathrm{Al} /$ steel joints can be illustrated with conceptual models in Fig. 11. The process includes melting, cutting and wetting, growing and breaking, and cooling.

After reaching the melting temperature of the filler metal, the liquefied Al-Si filler metal could not flow into the interspace of bonding joint by capillarity due to the oxide film on the surface of steel base metal. During the CAWB process, the oxide film was removed, and the fresh steel surface manifested a strong wetting reaction with the Al-Si molten filler metal. Different degrees of plastic deformation were achieved on the steel substrate as the number of cutting tool steps increased from four to seven, resulting in the macro self-locking structure at the interface. Especially the cutting tool step number was six, the micro-interface of the joint took on a serrated morphology, and the smallscale steel chips from the cutting process migrated in the molten pool.

With the progress of the joining process, IMCs has gradually grown on the regularly serrated interface into continuing and thick IMC layer, and the IMC particles wrapping with steel chips began to form in the molten pool. In this case, high-speed rotation of cutting tool was still stirring in the molten pool. According to the principles of the cutting process [16], the cutting forces $(F)$ can be decomposed into three different directions, namely, $F_{x}, F_{y}$ and $F_{z}$. With a suitable cutting force, the IMC thickness was reduced by the 6-step cutting tool. In addition, the cutting tool could force the $\mathrm{Si}$ element to fully react with the Fe-Al IMC layer and suppress the growth of reaction layer, which maximized the effect of Si element on the reduction of the IMC layer 
thickness. As a result, the microstructure of the serrated interface and the thin IMC thickness were beneficial in enhancing the mechanical properties of the joints.

In recent years, some particles with low CET have been added to the filler metal in an appropriate amount was investigated, which indicated that the lager different of CTE and Young's modules of dissimilar materials was reduced $[18,19]$. During the CAWB process, the IMC particles wrapping with high-melting-point steel chips and massive cutoff $\tau_{4}$ IMC particles with low CTE dispersive distribution in the welded seam. It would help to release the thermal stress and reduce the mismatch of the CET and Young's modules between steel and aluminum alloy.

\section{Conclusions}

(1) Cutting-assisted welding-brazing (CAWB) method without using of flux was proposed and applied in joining of aluminum alloy to stainless steel, and the cutting tool can disrupt and extrude the oxide film on the surface of steel.

(2) Taper step-shape cutting tools resulted in the severe plastic deformation on the steel substrate, which leading to the macro self-locking structure at the interface was realized. The value of interface wavelength could be $1999.4 \mu \mathrm{m}$ at the 2-step cutting tool, this was 3-4 times smaller than the ones at 2-step as the step number increased to 7-step.

(3) The joint interface made of 6-step cutting tool was distributed in a periodically serrated microstructure, which resulted in the micro self-locking structure at the interface. The thin and wavy IMC layer was identified as $\tau_{5}-\mathrm{Al}_{8}(\mathrm{Fe}, \mathrm{Cr})_{2} \mathrm{Si}$ phase with the minimum thickness of IMC layer was only approximately $3.3 \mu \mathrm{m}$.

(4) The dispersion distribution of $\tau_{4}$ IMC particles and $\mathrm{FeAl}_{6}$ phases on a small scale can be considered as reinforcement phases in the welded seam. The maximum tensile strength of joints produced by the 6-step cutting tool, reached $152.3 \mathrm{MPa}$, 
representing $75 \%$ of the 5052 aluminum alloy base metal.

Author contribution Huibin Xu: Conceptualization, Writing-original draft, Methodology, Funding acquisition. Wei Cong: Investigation, Methodology, Writing - original draft. Donghua Yang: Writing - review \& editing, Data curation. Yanlong Ma: Reviewing, Funding acquisition. Wanliang Zhong: Investigation, Methodology. Pan Tan: Investigation, Methodology. Jiuchun Yan: Methodology, Writing - review \& editing, Reviewing, Supervision.

Funding This project was supported by Basic Research and Frontier exploration project of Chongqing (the Natural Science Foundation of Chongqing) (No. cstc2018jcyjAX0705), The State Key Laboratory of Advanced Welding and Joining of China (No. AWJ-Z16-02), University Innovation Research Group of Chongqing (No. CXQT20023) and graduate Student Innovation Program of Chongqing University of Technology (No. ycx20192038).

Availability of data and material All data generated or analyzed during this study can be included in this published article. The experimental data in this article can be used for scientific research, teaching, etc.

Code availability Not applicable.

\section{Declarations}

Ethics approval The authors state that the present work is incompliance with the ethical standards.

Consent to participate and for publication All the authors listed have approved the manuscript, consented to participate, and consented for publication.

Conflicts of interest The authors declare no competing interests.

\section{References}

1. Wan L, Huang Y (2018) Friction welding of AA6061 to AISI 316L steel: characteristic analysis and novel design equipment. Int J Adv Manuf Technol 95:4117-4128.

2. Das T, Das R, Paul J (2020) Resistance spot welding of dissimilar AISI-1008 steel/Al-1100 alloy lap joints with a graphene interlayer. J Manuf Process 53:260-274.

3. Ma H, Qin G, Bai X, et al (2016) Effect of initial temperature on joint of aluminum alloy to galvanized steel welded by MIG arc brazing-fusion welding process. Int J Adv Manuf Technol 86:3135-3143.

4. Yuan R, Deng S, Cui H, et al (2019) Interface characterization and mechanical properties of dual beam laser welding-brazing Al/steel dissimilar metals. J Manuf Process 40:37-45. 
5. Furuya HS, Sato YT, Sato YS, et al (2018) Strength Improvement Through Grain Refinement of Intermetallic Compound at $\mathrm{Al} / \mathrm{Fe}$ Dissimilar Joint Interface by the Addition of Alloying Elements. Metall Mater Trans A Phys Metall Mater Sci 49:527-536.

6. He H, Wu C, Lin S, Yang C (2019) Pulsed TIG Welding-Brazing of Aluminum-Stainless Steel with an Al-Cu Twin Hot Wire. J Mater Eng Perform 28:1180-1189.

7. Wu K, Yuan X, Li T, et al (2019) Effect of ultrasonic vibration on TIG welding-brazing joining of aluminum alloy to steel. J Mater Process Technol 266:230-238.

8. Xu H, Gao P, Cong W, et al (2019) Arc joining of aluminium alloy to stainless steel with the aid of milling. Mater Sci Technol 35:107-115.

9. Hirata T, Li P, Lei F, et al (2019) Epoxy nanocomposites with reduced coefficient of thermal expansion. J Appl Polym Sci 136:1-6.

10. Rivera J, Hosseini MS, Restrepo D, et al (2020) Toughening mechanisms of the elytra of the diabolical ironclad beetle. Nature 586:543-548.

11. Gupta SP (2003) Intermetallic compound formation in Fe-Al-Si ternary system: Part I. Mater Charact 49:269-291.

12. Chen J, Shalchi Amirkhiz B, Zhang R, Rona B (2020) On the Joint Formation and Interfacial Microstructure of Cold Metal Transfer Cycle Step Braze Welding of Aluminum to Steel Butt Joint. Metall Mater Trans A Phys Metall Mater Sci 51:5198-5212.

13. Chama CC (1996) Distribution of $\mathrm{Al}_{12} \mathrm{Fe}_{3} \mathrm{Si}$ and $\left(\mathrm{FeAl}_{6}\right) \mathrm{Si}$ in a HIPed $\mathrm{Al}-10.71$ wt.\% Si casting. Mater Charact 37:177-181.

14. Barmak K, Dybkov VI (2004) Interaction of iron-chromium alloys containing 10 and 25 mass $\%$ chromium with liquid aluminium Part II Formation of intermetallic compounds. J Mater Sci 39:4219-4230.

15. Song XG, Cao J, Wang YF, Feng JC (2011) Effect of Si3N4-particles addition in Ag-Cu-Ti filler alloy on $\mathrm{Si}_{3} \mathrm{~N}_{4} / \mathrm{TiAl}$ brazed joint. Mater Sci Eng A 528:5135-5140.

16. Budak E (2006) Analytical models for high performance milling. Part I: Cutting forces, structural deformations and tolerance integrity. Int J Mach Tools Manuf 46:1478-1488.

17. Yang J, Yu Z, Li Y, et al (2018) Influence of alloy elements on microstructure and mechanical properties of Al/steel dissimilar joint by laser welding/brazing. Weld World 62:427-433.

18. Kim BG, Dong SL, Park SD (2001) Effects of thermal processing on thermal expansion coefficient of a 50 vol.\% SiCp/Al composite. Mater Chem Phys 72:42-47.

19. Gorsse S, Petitcorps Y Le, Matar S, Rebillat F (2003) Investigation of the Young's modulus of TiB needles in situ produced in titanium matrix composite. Mater Sci Eng A 340:80-87. 


\section{List of Captions:}

Table 1 Chemical composition of 304 stainless steel and 5052 aluminum alloy (wt.\%).

Table 2 Chemical composition of 4043 filler metal (wt.\%).

Table 3 EDS results of points A-F in Fig. 6.

Table 4 EDS results of points A-C in Fig. 8.

Fig. 1. Schematic of butt welding of aluminium alloy to steel with CAWB process.

Fig. 2. The Schematic of cutting tool: (a) taper-shape; (b) taper step-shape.

Fig. 3. The geometry of tensile specimen, unit: $\mathrm{mm}$.

Fig. 4. The cross-section of the joint without cutting tool.

Fig. 5. The CAWB joints morphologies at (a) taper cutting tool, (b) 4-step, (c) 6-step, (d) 7-step, (e) the schematic diagram of wavelength and amplitude and (f) relationship among cutting tool profiles, wavelength and amplitude.

Fig. 6. The microstructure of joints interface:(a-b) taper cutting tool; (c-d) 4-step; (e-f) 6-step; (g-h) 7-step.

Fig. 7. (a) EDS line scanning results of IMC layer at 6-step cutting tool; (b) the IMC thickness of joints at different cutting tool.

Fig. 8. Microstructure of the welded seam at: (a, b) without cutting tool; (c, d) taper cutting tool; (e, f) 6-step cutting tool.

Fig. 9. Relationship between precipitated phase ratio and cutting tool profiles.

Fig. 10. (a) Graph of the joints tensile strength at different cutting tool profiles, (b) XRD pattern of the steel fracture surface.at 6-step, (c) fracture surface at the steel side and (d) high magnification SEM of area d.

Fig. 11. Conceptual model of the new CAWB process for joining Al/steel with 6-step cutting tool. 
Table 1 Chemical composition of 304 stainless steel and 5052 aluminum alloy (wt.\%).

\begin{tabular}{ccccccccccccc}
\hline Alloys & $\mathrm{C}$ & $\mathrm{Si}$ & $\mathrm{Cu}$ & $\mathrm{Mg}$ & $\mathrm{Cr}$ & $\mathrm{Ni}$ & $\mathrm{Mn}$ & $\mathrm{Zn}$ & $\mathrm{S}$ & $\mathrm{P}$ & $\mathrm{Fe}$ & $\mathrm{Al}$ \\
\hline $\mathrm{Al}$ & - & 0.25 & 0.1 & 2.5 & 0.15 & - & 0.1 & 0.1 & - & - & 0.4 & Bal. \\
Steel & 0.08 & 1.0 & - & - & $18.0-20.0$ & $8.0-11.0$ & 2.0 & - & 0.03 & 0.045 & Bal. & - \\
\hline
\end{tabular}

Table 2 Chemical composition of 4043 filler metal (wt.\%).

\begin{tabular}{ccccccccc}
\hline Alloys & $\mathrm{Si}$ & $\mathrm{Fe}$ & $\mathrm{Cu}$ & $\mathrm{Mn}$ & $\mathrm{Mg}$ & $\mathrm{Zn}$ & $\mathrm{Ti}$ & $\mathrm{Al}$ \\
\hline ER4043 filler metal & $4.5-5.0$ & 0.8 & 0.3 & 0.05 & 0.05 & 0.1 & 0.2 & Bal. \\
\hline
\end{tabular}

Table 3 EDS results of points A-F in Fig. 6.

\begin{tabular}{cccccc}
\hline \multirow{2}{*}{ Point } & \multicolumn{4}{c}{ Elements (at.\%) } & \multirow{2}{*}{ Possible phase } \\
\cline { 2 - 5 } & $\mathrm{Fe}$ & $\mathrm{Si}$ & $\mathrm{Cr}$ & $\mathrm{Al}$ & \\
\hline $\mathrm{A}$ & 20.27 & - & 3.91 & 75.82 & $\theta-\mathrm{Fe}_{4} \mathrm{Al}_{13}$ \\
$\mathrm{~B}$ & 15.99 & 7.09 & 3.73 & 73.19 & $\tau_{5}-\mathrm{Al}_{8}(\mathrm{Fe}, \mathrm{Cr})_{2} \mathrm{Si}$ \\
$\mathrm{C}$ & 11.10 & 8.26 & 5.04 & 75.60 & $\tau_{4}-(\mathrm{Fe}, \mathrm{Cr})(\mathrm{Al}, \mathrm{Si})_{5}$ \\
$\mathrm{D}$ & 13.97 & 10.16 & 4.35 & 71.52 & $\tau_{5}-\mathrm{Al}_{8}(\mathrm{Fe}, \mathrm{Cr})_{2} \mathrm{Si}$ \\
E & 20.13 & 8.52 & 6.04 & 65.31 & $\eta-(\mathrm{Fe}, \mathrm{Cr})_{2}(\mathrm{Al}, \mathrm{Si})_{5}$ \\
F & 13.10 & 11.53 & 4.58 & 70.79 & $\tau_{5}-\mathrm{Al}_{8}(\mathrm{Fe}, \mathrm{Cr})_{2} \mathrm{Si}$ \\
\hline
\end{tabular}

Table 4 EDS results of points A-C in Fig. 8.

\begin{tabular}{cccccc}
\hline \multirow{2}{*}{ Point } & \multicolumn{4}{c}{ Elements (at.\%) } & \multirow{2}{*}{ Possible phase } \\
\cline { 2 - 5 } & $\mathrm{Fe}$ & $\mathrm{Si}$ & $\mathrm{Cr}$ & $\mathrm{Al}$ & \\
\hline $\mathrm{A}$ & - & 11.04 & - & 88.96 & $\mathrm{Al}-\mathrm{Si}$ eutectic \\
$\mathrm{B}$ & 11.8 & - & 2.12 & 86.08 & $\mathrm{FeAl}_{6}$ \\
$\mathrm{C}$ & 12.11 & 7.48 & 4.35 & 76.06 & $\tau_{4}-(\mathrm{Fe}, \mathrm{Cr})(\mathrm{Al}, \mathrm{Si})_{5}$ \\
\hline
\end{tabular}




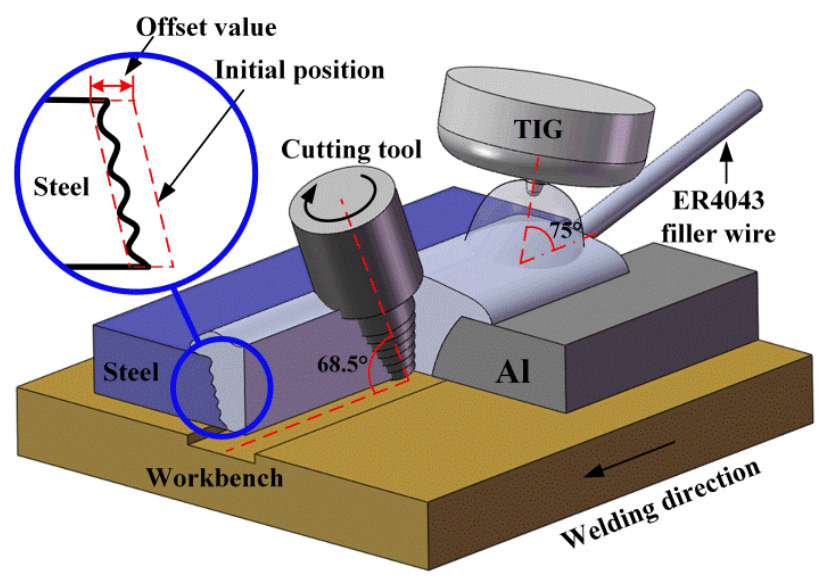

Fig. 1. Schematic of butt welding of aluminium alloy to steel with CAWB process.
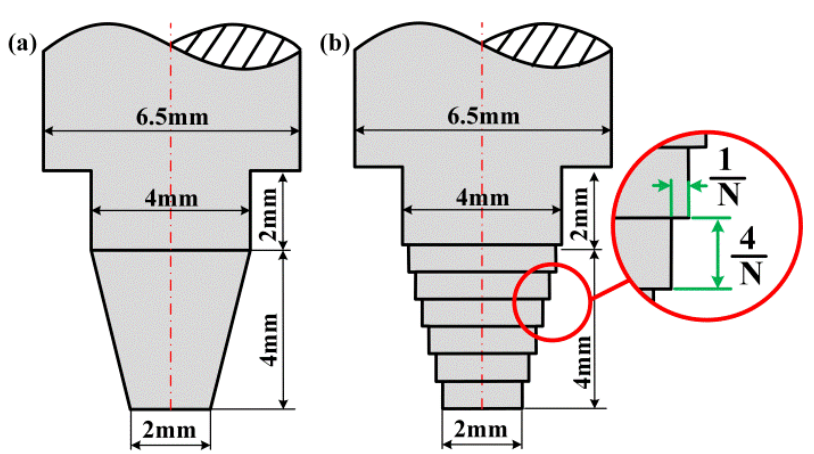

Fig. 2. The Schematic of cutting tool: (a) taper-shape; (b) taper step-shape.

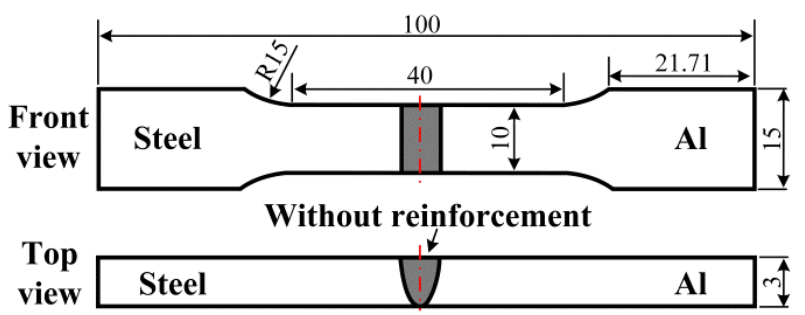

Fig. 3. The geometry of tensile specimen, unit: $\mathrm{mm}$.

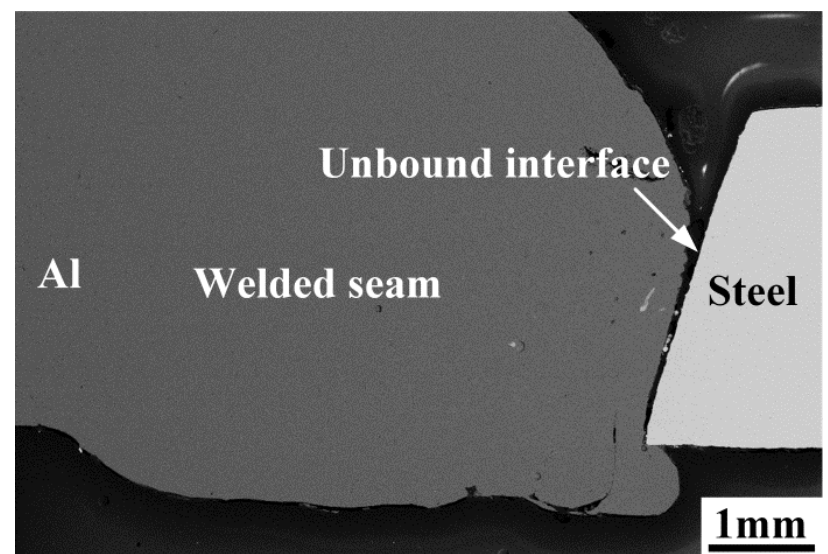


Fig. 4.The cross-section of the joint without cutting tool.
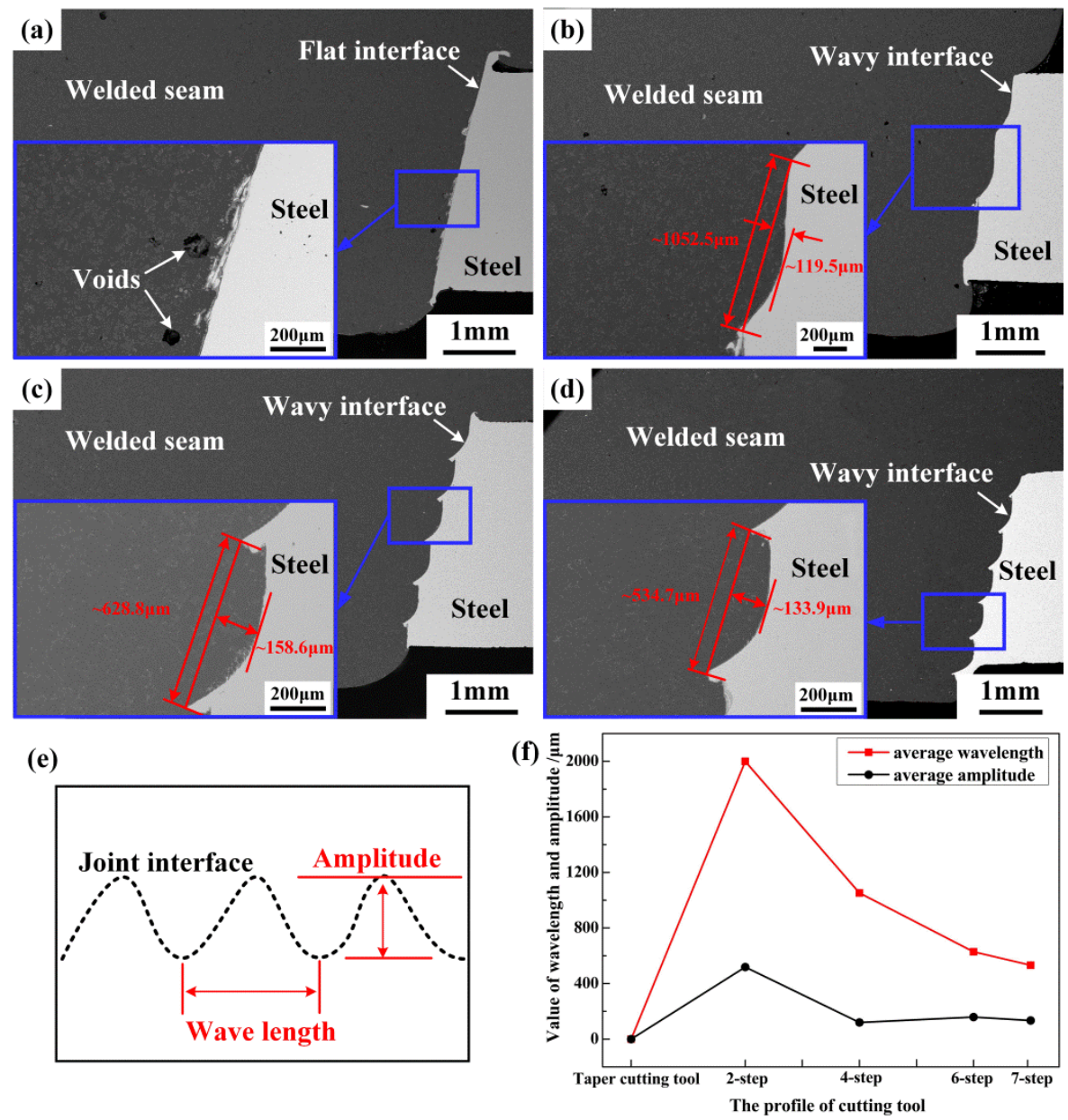

Fig. 5. The CAWB joints morphologies at (a) taper cutting tool, (b) 4-step, (c) 6-step, (d) 7-step, (e) the schematic diagram of wavelength and amplitude and (f) relationship among cutting tool profiles, wavelength and amplitude. 

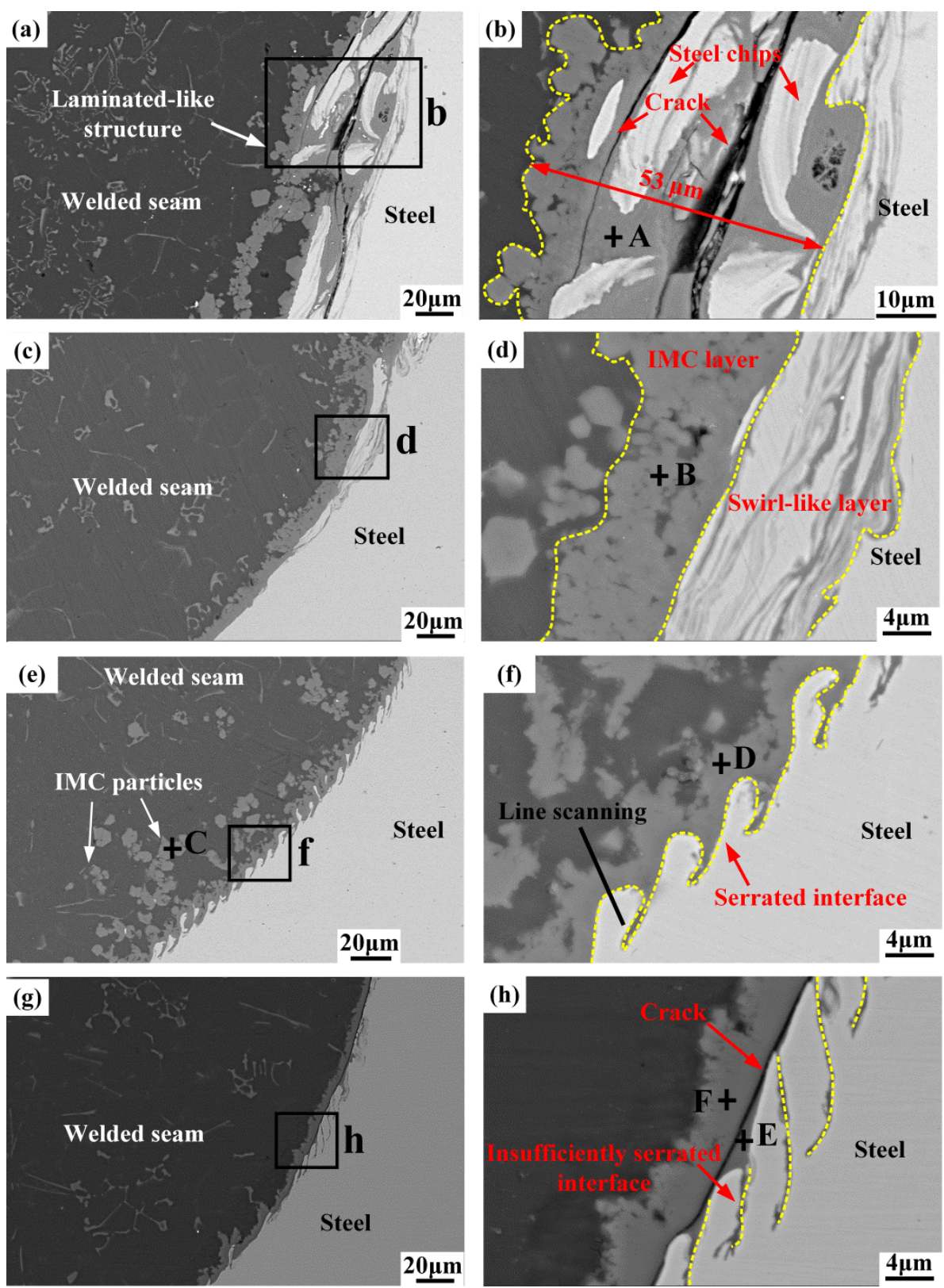

Fig. 6. The microstructure of joints interface:(a-b) taper cutting tool; (c-d) 4-step; (e-f) 6-step; (g-h) 7-step.
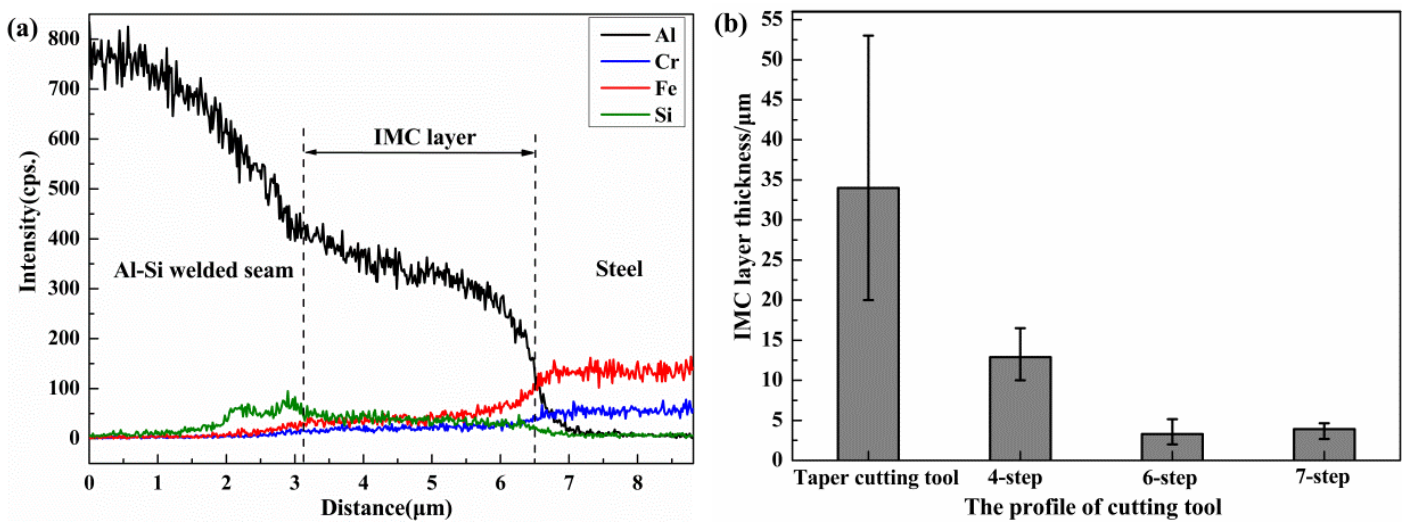
Fig. 7. (a) EDS line scanning results of IMC layer at 6-step cutting tool; (b) the IMC thickness of joints at different cutting tool.
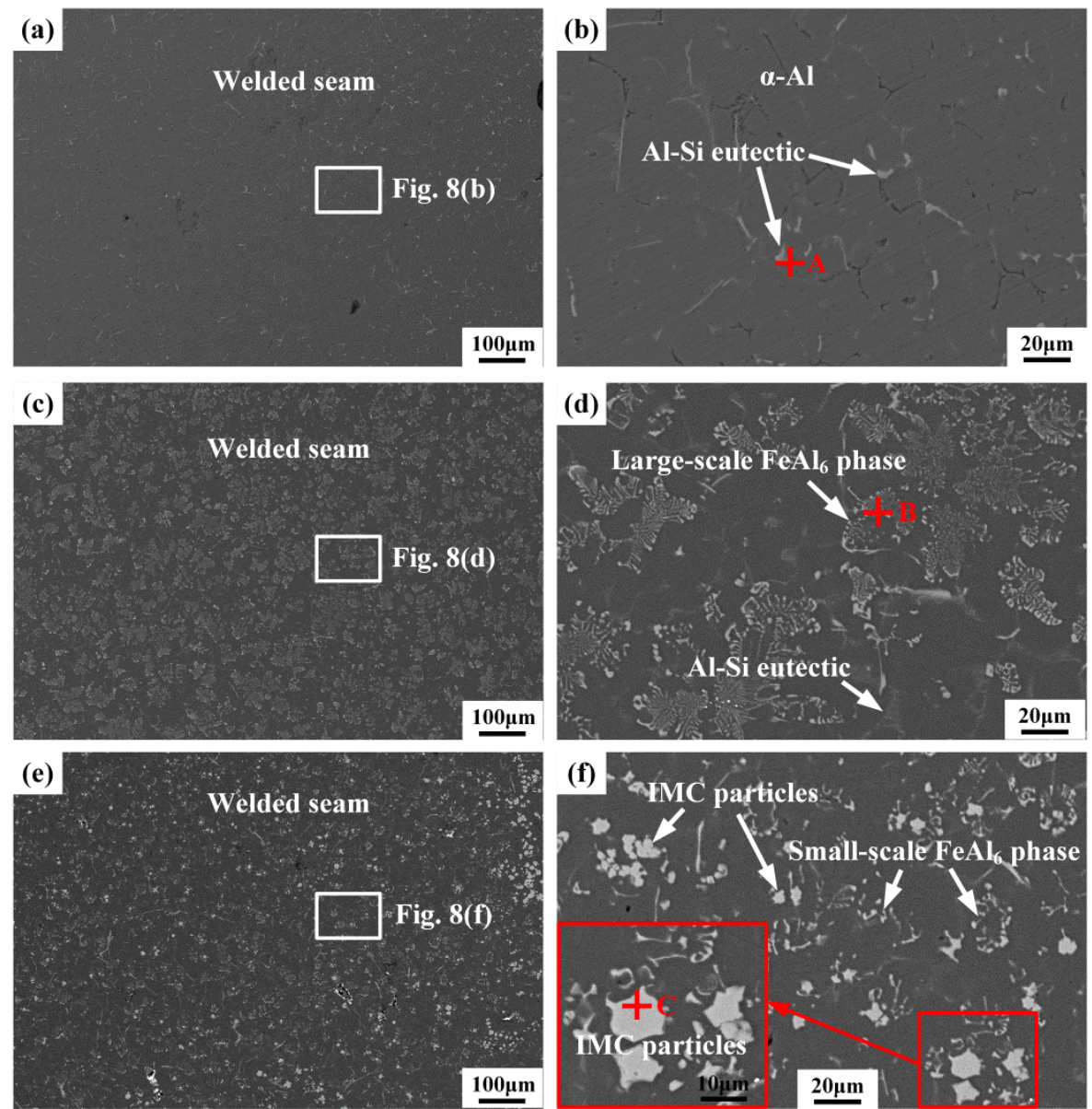

Fig. 8. Microstructure of the welded seam at: $(\mathrm{a}, \mathrm{b})$ without cutting tool; $(\mathrm{c}, \mathrm{d})$ taper cutting tool; (e, f) 6-step cutting tool.

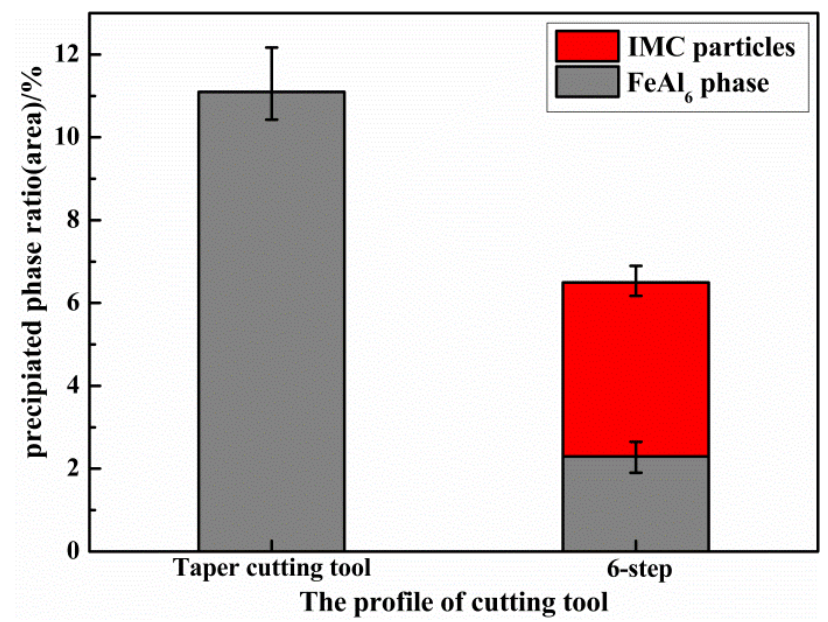

Fig. 9. Relationship between precipitated phase ratio and cutting tool profiles. 

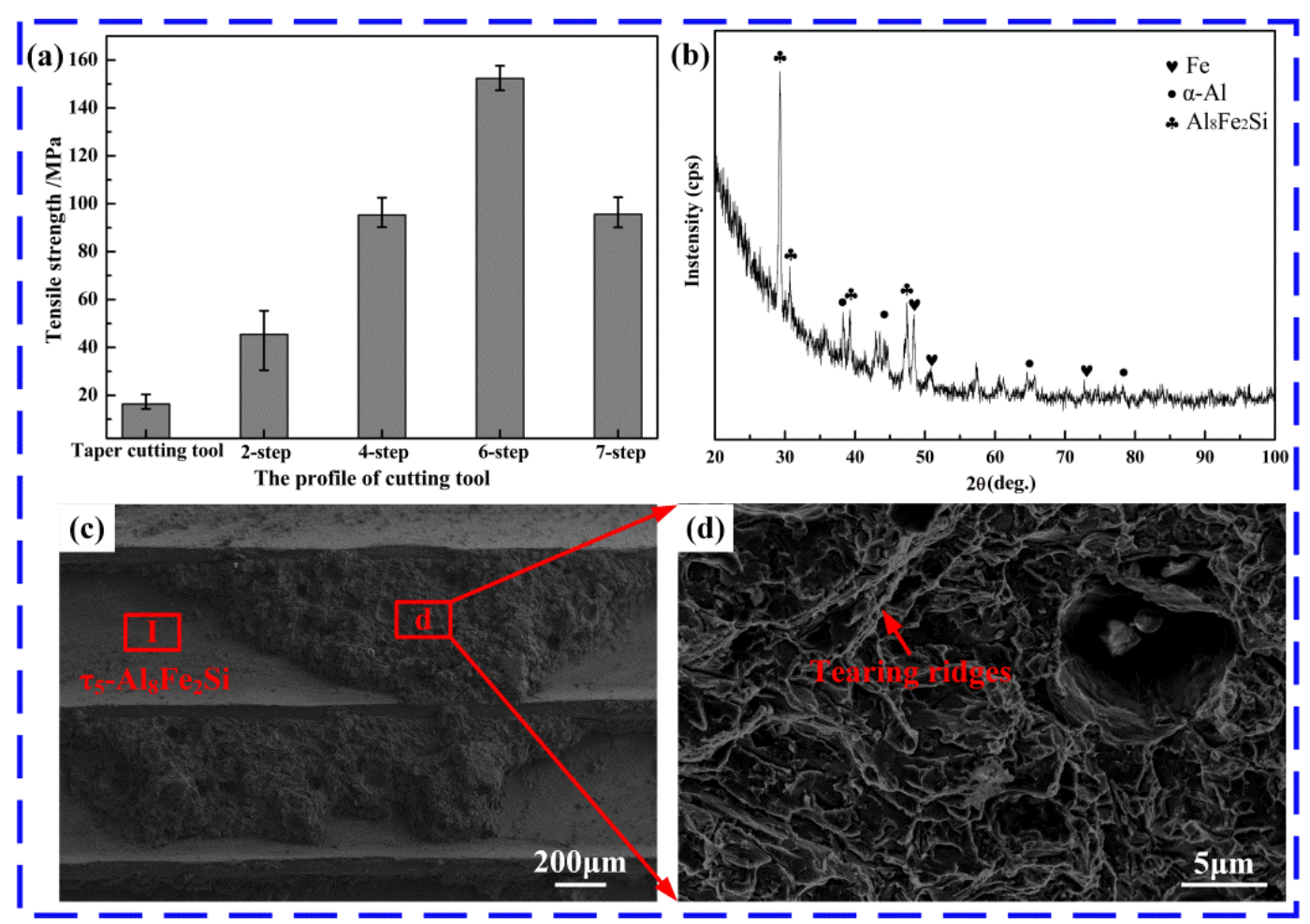

Fig. 10. (a) Graph of the joints tensile strength at different cutting tool profiles, (b) XRD pattern of the steel fracture surface.at 6-step, (c) fracture surface at the steel side and (d) high magnification SEM of area d.

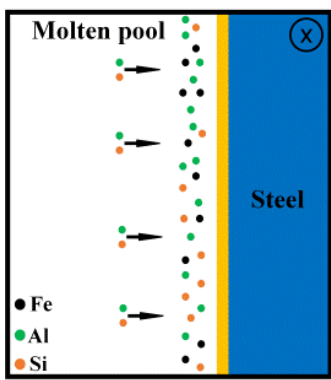

Melting

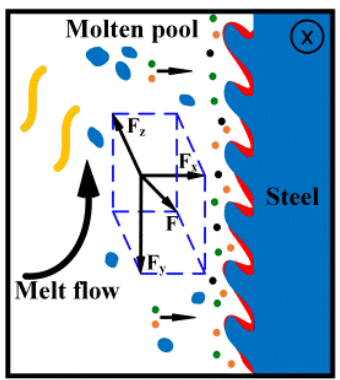

Cutting and wetting

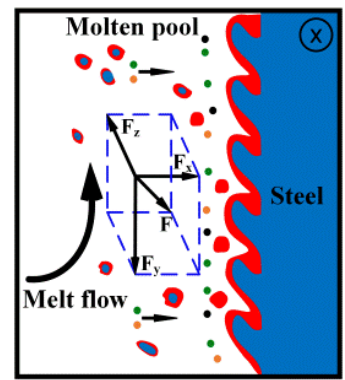

Growing and breaking

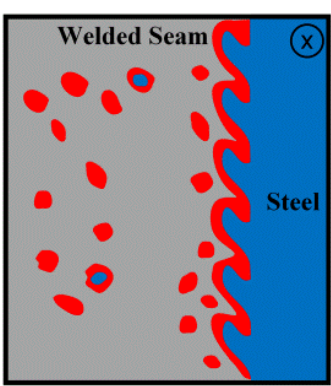

Cooling

\section{:Steel :Steel particle :oxide film @:Welding direction}

:Reaction layer :IMC particle $\quad$ :IMC particle wrapping with steel

Fig. 11. Conceptual model of the new CAWB process for joining Al/steel with 6-step cutting tool 